"Przegląd Prawa Konstytucyjnego"

------ Nr $3(19) / 2014$------

\title{
Komunikat
}

\section{Rights and services for a new Europe of the citizens}

The economic crisis of the early twenty-first century appears, today, as one the most obvious examples of the negative effects of the lack of real political integration in the EU.

As we know - since the Maastricht Treaty - the monetary and economic integration was not followed by what was supposed to be a natural evolution of the European Communities in an effective „political union”, democratically legitimized.

The lack of a full and direct European governance, deepened by the increasingly marked distinction between the Eurozone and the European Union, seems to be the main cause of the European system weaknesses, overwhelmingly arisen with the spread of the U.S. crisis, which made Europe face the need to strengthen governance, at least economic, within the only Eurozone, making even more marked the differences between the Member States which do not adopt the single currency.

The signs that reinforce this conclusion are numerous.

First: the concentration of a great influence in the hands of the ECB (which is found, in fact, to operate more as a "political actor" than as a Central Bank). Moreover, the series of interventions aimed at tackling the market pressures on the public debt [the Security Market Program (SMP), then replaced by the Outright Monetary Transactions program (OMT)], and support to countries in difficulty [with the establishment of the European Financial Stabilization Mechanism (EFSM), the European Financial Stability Fund (EFSF) and subsequently the European Stability Mechanism (ESM)], has gradually led to a transformation of the Eurozone in a "community of 
risk", with significant advances, in terms of the intensity of community ties, in a process that is now substantially configured as constitutional.

This process was characterized by a strong interaction between National (both politics and constitutional justice) and European institutions: a dialogue leading to the adoption of Euro Plus Pact in 2010, and later the so called Six packs, Two packs and Fiscal compact, with a strengthening of the Commission control on national budgets to the point of ensuring that Eurozone Countries introduce the principle of „balanced budget” in their rules ${ }^{1}$. These constraints and economic rules, however, are not perceived by the collectivity as democratically legitimate political decisions.

The measures and the constraints assumed during the European emergency process - or, rather, solely within the Eurozone - represent an unprecedented level of integration, not limited only to the economic governance. However, since the (technical) economic rules, taken by the experts, produce effects on single Countries political choices, even before than European ones, it seems now urgent the need of solve the democratic deficit in the EU, repeatedly pointed out - but still today not solved.

Obviously, it is not easy to imagine solutions. It is desirable that, the economic and political crisis which crosses - we can say across the board - (not only, but) also the States of the European Union should be overcome by improving living conditions of the „citizens of the Union”, and strengthening democracy in Europe. In essence, the political and economic crisis of these Nations may allow a further step forward in the development of supranational integration.

My impression is that, today, the public attention is mainly attracted by the economic dimension of the current situation. The economic one, however, is not the only aspect of the crisis, nor for the States, nor for the development of the European Union.

The crisis, which is gripping in particular Italy, not only depends on the "state of the public finances", but above all, on a strong loss of credibility in the „political representation”. The result is that , to get out of this negative situation, it is necessary before anything else, just to recover that national identity ,inherent in (...) the fundamental structures, political and constitu-

${ }_{1}$ On topic, recently, E. Raffiotta, Il governo multilivello dell'economia, Bologna, BUP, 2013. 
tional". This latter makes express mention in the Treaty on European Union (art. 4.2), since this national identity is essential, not only for our country, but for the further development of the European integration project, that is based on the maintenance of different and various constitutional rules.

It has never happened (as it happens nowadays) that, the strength of the Union also depends heavily on the strengthening of institutional and constitutional mechanisms within States, on whom depend in turn a well-defined „Constitutional identity”. As regards the current Italian situation, it still lacks (due to non-completion of constitutional reforms) from two points of view: the form of government, and the decentralized structure of the State. I am referring in particular to the necessity of redesigning a new structure of the Senate, which has to better reflect the strengthening of local governments.

A few days ago, at the University of Catania, on the occasion of the opening of Jean Monnet Course Public Services, fundamental rights, European constitutionalism, under my coordination, a cue was debated on what may help us on this discussion. We have done a reference to a thesis, recently argued by a well-known Italian constitutional law scholar ${ }^{2}$, according to which every „political unity” is necessarily based on three essential elements: the economy, the culture and the government.

Without prejudice to the surely relevant first element, I mean economy, I believe that today both EU and Member States, in their own role, should enhance the value of the second and third elements: culture and government.

We have endeavored to seek a solution to the problem of economic and financial recession. Someone has found it in the so called "austerity”, others in a neo-Keynesian idea of government intervention on the economy, and others in the so called „Exit from the Euro”. We did not try, however, to really deal with the actual lack of „civic participation” of citizens in the Institutions of the Union. This is the inevitable consequence: the deficiency of the essential civic and cultural legitimacy, which can give in fact force to the idea of strong government.

Moreover, we cannot forget that only a strong government, by virtue of strong legitimacy, can put in the field unique and compelling , anti-crisis solutions".

${ }^{2}$ G. Zagrebelsky, Fondata sulla cultura, Torino-Einaudi 2014. 
Then, the circle may be closed: without „European civic conscience” there is no legitimacy and, therefore, the well-known „substantial democratic deficit" comes to lights. Without legitimacy cannot be a strong idea of government, and without a strong government we cannot solve the economic and financial downturn, nor within the States, nor in the broader continental context.

It is urgent, first of all, that the citizens of the Member States take conscience of their own legal status, I mean European citizenship, and develop its potentialities. Secondly, we can use a chemistry metaphor, in the shortest time possible, they should be placed in a position to be the components of a "single solution" (the people of Europe), and not mere components of a "mixture” (the set of European peoples). From this point of view, it is desirable and essential a common status concerning the use of "general economic interest-services", as well as non-economic ones: I think, certainly, about the administration of justice, just to start a decisive step forward in the construction of the "civic” contents of European citizenship.

In this sense we identify the constitutional profile linked to the emersion of those values which inspire the EU rules: it can be argued, in fact, that the "European constitutional law” provides the legal instruments of mediation between the (still in progress) process of integration and national rules, in a circular and mutual exchange, considering the national citizens as part of a single and larger „community of law ,; this latter is meant, however, not as a political order in the proper sense, but as a "person” who pursues political choices in the various areas recognized by the Treaties, whereas the public authorities are engaged in situations of private freedom ${ }^{3}$.

It does not seem relevant, under this aspect, that the involved individuals (the Europeans citizens) do not give birth to a people in a technical sense because of the non-political and non-general purposes of the institution we are talking about. The "political choices”, in fact - with more and more wide-ranging - are prefigured beyond closely productivistic areas, such as the case of the common foreign and security policy (CFSP); or the judicial cooperation in civil matters, which also provides the adoption of Community

${ }^{3}$ In argument, E. Castorina, Riflessioni sul processo costituente europeo, Turin-Giappichelli 2010. 
measures for the approximation of the rules and regulations of the Member States; or also the judicial cooperation in criminal matters, under which the European Parliament and the Council may establish substantial (and, therefore, not only with a procedural nature) „minimum rules” in guarantee of the involved parties.

Then we can well understand that, if an entity wants to emerge as a 'community', obviously it must tend to identify itself in a set of „values”; and to which it must make constant reference through its political choices. This is the sense of Art. 2 of the new Treaty on EU, which aims to highlight - through a "super-rule " of European law - the „common values, on which the Union is founded, because they characterize the contemporary pluralistic societies and, therefore, they are able to guide the gradual formation of a new and larger "demos" (that is „people”) through the social integration of the various peoples of Europe.

We have an opportunity that could work in favor: next European elections in the spring. Approaching the political competition for Europe, citizens of the Member States should change the perspective with whom they have looked at the electoral competition until nowadays, from a purely „internal” vision to a „common” one. For example: if an Italian voter chooses to vote for a candidate of a national party, he/she should be aware of the fact that he/she is expressing a preference in favor of the group where this (national) party which will converge into the European Parliament.

The strengthening of the „civic and social content of European citizenship" depends, first of all, on the development of a "common culture" of citizens of the Member States. It may take the form only if they live in a context where the fundamental rights and social rights can be enjoyed in conditions of actual equality in the whole of the territory of the EU. The level of substantial legitimacy of the Institutions of the Union depends, in turn, on this „common culture”, meant as the base-value which can give form to a wider political legitimacy of the Institutions representing the European Union.

More clearly, invigorated thanks to a so strong investiture, the Institutions would have the possibility and the power-duty to make those clear and unambiguous choices, which can make a significant step change in the anti-crisis strategy. 
Just consider art. 14 TFEU. It should be noted that this provision provides for the placement of services of general economic interest „,in the shared values of the Union”, specifically for the role they can play in „promoting social and territorial cohesion", which is one of the integration goals: this aspect testifies the centrality of discipline regarding public services for the construction of an "European society”, in which the reference to the values of the Union shows the constitutional heritage that sustains and gives foundation to the supranational "community of law”.

Equally eloquent in this regard is the provision contained in art. 106 of the Treaty, according to which the undertakings entrusted with the operation of services of general economic interest (not the services of non-economic importance) are subjected to the rules of the competition, although not in an absolute sense, but „in so far as the application of such rules does not obstruct the performance, in law or in fact, of the particular tasks assigned to them". In these cases, then, we may well justify the interest of the Member State in using certain undertakings as an instrument of economic or social policy; this interest must be balanced against the duty to observe the rules of the competition and the preservation of the unity of the market inside.

It's well known that the European legal system is characterized by the neutrality of the ownership regime in force within the Member States (Art. 345 TFEU), also with respect to the legal form of public undertakings entrusted with a public service; in fact European law does not require, as a mandatory requirement, the privatization of the economic services; moreover it's up to the Member States the distinction, within their legal systems, between economic and non-economic activities.

We can appreciate the need to establish a balance of principles that support the „integrated European economy law”; it is necessary to converge in this point of balance both needs of the market and the competition, as those of an equal satisfaction of basic and social rights, that are destined to intertwine with the very considerable demands of the competitive market. We must not forget that in the national legal systems the protection of the competition is a duty exclusively reserved to the State (in accordance with Art. 117 , paragraph 2 , letter e, being equally functional for the freedom of economic initiative recognized to everyone and for the general interest of the community; furthermore the definition of the competition rules, necessary for 
the functioning of the internal market, are an exclusive competence of the Union, Art. 3, paragraph 1, lett. b).

Both the Lisbon Treaty and the Charter of Fundamental Rights of the EU promote the social and territorial cohesion of the Union, recognizing that the access to services of general economic interest is fundamental, as provided for by national rules and practices.

The ultimate aim should be the establishment of a "common European statute of services of general economic interest" - not less than the non-economic interest ones-: above all, I think about the administration of justice, in order to recover the efficiency and the effectiveness standards common to the Member States. It would be desirable if the Union provided in that sense, since it has concurrent jurisdiction with the Member States in the field of economic, social and territorial cohesion (art. 4, paragraph 2, letter. c, TFEU).

In essence, the building of the European citizenship in terms of civic substance and solidarity, should lead to a further step by the EU, which goes beyond the formal „recognition" and "respect” of the rules and the national practices, in accordance with the provisions of art. 36 of the Charter, in order to ensure an equal level of fruition of the public services within the Member States and, therefore, a condition of equal fruition of the involved social rights, overcoming in this way a clear reluctance of Article 36 of the mentioned Charter of Nice.

In my opinion, the objections from observers, political parties and civil society movements who claim an anti-European position, according to which any action or several actions of the European Institutions in the field is equivalent to a swallowed in the internal affairs of each State, are unfounded. The „strengthening of the civic and social content of European citizenship" may be the only possible vehicle to legitimate, from below, the European Institutions.

The "national sovereignty at all costs" is no longer a topic on which we can bet with assurance if we really care of the future of the European Union.

Emilio Castorina University of Catania 